\title{
LASER SURFACE ALLOYING OF A MILD STEEL FOR CORROSION RESISTANCE IMPROVEMENT
}

\author{
F. FOUQUET, L. RENAUD, J.P. MILLET* and H. MAZILLE* \\ INSA, GEMPPM-CALFETMAT, Bât. 502, F-69621 Villeurbanne cedex, France \\ *INSA, LPCI, Bât. 401, F-69621 Villeurbanne cedex, France
}

\begin{abstract}
Surface alloys were produced by laser melting of different predeposits into the outer part of a mild steel substrate. Three types of coatings were used : electroless nickel (containing phosphorous), electroless nickel in which chromium carbide particles were introduced during deposition and duplex coatings made of, first, a nickel layer (electroless or electrodeposited) and then, a chromium layer. The surface alloying treatments were performed using a cw high power $\mathrm{CO} 2$ laser and the multiple track melting technique with $60 \%$ overlap between each track. A single laser scan was used. The obtained surface alloys show excellent adherence without porosity or cracking. A detailed microstructural investigation revealed a fine dendritic microstructure. Phosphorous, when present, is segregated in the interdendritic areas. The corrosion resistance of the surface alloys was tested by electrochemical techniques in various neutral or acidified saline media deaerated or naturally aerated. With the first type of predeposit, surface alloys exhibit a corrosion resistance similar to that of electroless nickel but with a much higher adherence of the coating to the substrate. With the second type of predeposit, the increase in corrosion resistance is limited due to the low chromium concentration obtained in solid solution. On the contrary with the third type of predeposits (duplex layers), surface alloys exhibit a high corrosion resistance especially when electrolytic nickel coating was used.
\end{abstract}

\section{Introduction}

Electroless nickel coatings are very interesting for corrosion protection of mild steel [1]. Moreover they have the advantage compared to electrodeposits to be easily realized with an homogeneous thickness. But sometimes cracks, pores or lack of adherence may decrease the effectiveness of the corrosion protection [2]. The possibility of using laser treatment to enhance the protectiveness of electroless nickel deposits was then examined. The first step was to eliminate the cracks and pores, and to enhance the adherence, without decreasing the corrosion resistance by laser melting the coating together with a thin layer of substrate. If this can be achieved and controlled, other elements, such as chromium, can be incorporated in order to enhance the corrosion resistance properties.

The present paper is a short presentation of the results concerning laser surface melting of mild steel precoated with electroless nickel, electroless nickel containing chromium carbide particles and dual deposits composed of a nickel layer plus an electroplated chromium one. For these dual coatings, nickel was either electroless or electroplated. More detailed informations have been published elsewhere [3-6].

\section{Experimental Procedure}

Samples are XC10 grade steels (AISI 1010). Electroless nickel deposits contain about 8-9 wt \% phosphorous. In some of them $\mathrm{Cr} 3 \mathrm{C} 2$ chromium carbide particles were incorporated; their size varying from a few tenth of $\mu \mathrm{m}$ to $10 \mu \mathrm{m}$. 
Laser treatment was performed with a continuous CO2 laser (CILAS CI 4000) allowing a power (P) from $300 \mathrm{~W}$ up to $3.5 \mathrm{~kW}$. Samples were fixed on a numerically controlled $X-Y$ table, the displacement speed (VT) could be adjusted from 0.1 to $300 \mathrm{~mm} \cdot \mathrm{s}^{-1}$. The laser beam is focused by a $\mathrm{ZnSe}$ lens. The specimen-lens distance is adjusted to have a beam diameter at the impact point of about $0.6 \mathrm{~mm}$. The whole specimen surface is treated by moving the sample under the beam. For that, a serie of partially overlapping passes must be made. An interpass distance of $0.15 \mathrm{~mm}$ was used for all the treatments.

Microstructural analysis was performed by optical micrography after etching in nital $3 \%$, by scanning electron microscopy using back scattered electrons on polished and unetched samples, by electron microprobe analysis (X-ray mapping and concentration profiles), by $\mathrm{X}$-ray diffraction and by transmission electron microscopy.

The corrosion behaviour was investigated using electrochemical techniques in deaerated $0.1 \mathrm{M}$ $\mathrm{Na} 2 \mathrm{SO} 4$ solutions (neutral and $\mathrm{pH}=3$ ) and in $30 \mathrm{~g} / \mathrm{NaCl}$ solutions (deaerated or not).

\section{Results and Discussion}

For each type of coating, optimization of treatment parameters $(\mathrm{P}, \mathrm{VT})$ was performed in order to obtain surface alloys of uniform thickness, free of cracks and pores, and adherent to the substrate.

\section{Electroless Nickel}

Figure 1a shows the example of a laser surface alloy obtained from a $75 \mu \mathrm{m}$ thick electroless nickel deposit. The mean thickness of the melted layer is $130 \mu \mathrm{m}$ which corresponds to nickel content of about 60 $\%$ by weight. Figure $1 \mathrm{~b}$ shows a typical microstructure for this type of surface alloy. All the obtained microstructures were dendritic or cellular with a plane front growth region at the substrate-melt interface. The interdendritic distance decreases with increasing solidification rate. The results obtained with the different investigation techniques are the following : dendrites contain essentially $\mathrm{Fe}$ and $\mathrm{Ni}$, mainly in austenitic structure (or austenite + ferrite, for important melted depths). Phosphorous is strongly segregated in interdendritic areas forming an eutectic compound fcc (Fe-Ni) + tetragonal (Fe, Ni)3 P. It can be noted that in spite of high cooling rates (about $10^{5} \mathrm{~K} . \mathrm{s}^{-1}$ ) the microstructures are in agreement with the equilibrium phase diagrams. Moreover, the $\mathrm{Fe}$ and $\mathrm{Ni}$ distributions are macroscopically uniform, which means that a good homogeneization took place during the melting stage.

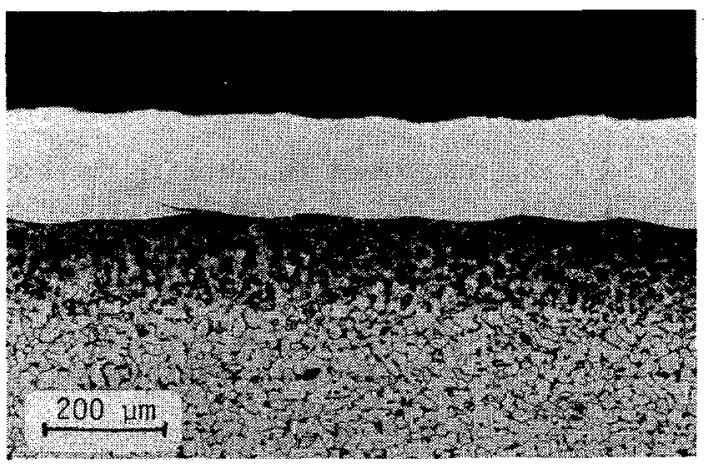

(a)

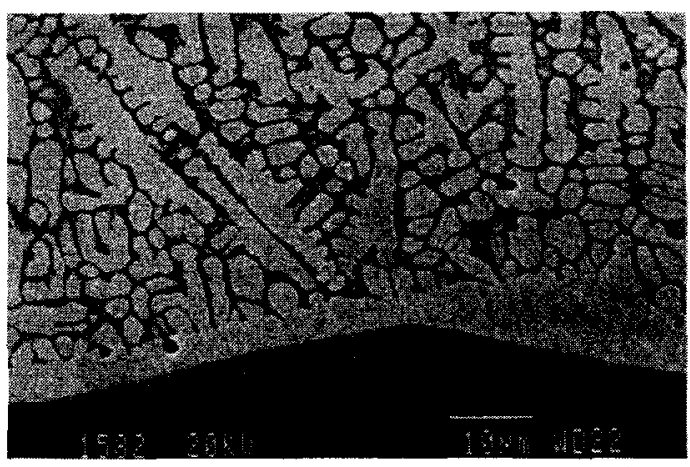

(b)

Fig. 1. Example of $\mathrm{Fe}-\mathrm{Ni}$ - $\mathrm{P}$ laser surface alloy a - Cross section optical micrograph, $\mathrm{b}$ - Back scattered electron image

Figure 2 is relative to the electrochemical behaviour in the two most agressive media of the laser treated samples I, II and III obtained with the same VT $\left(20 \mathrm{~mm} \cdot \mathrm{s}^{-1}\right)$ but with an increasing power respectively $960 \mathrm{~W}, 1080 \mathrm{~W}$ and $1200 \mathrm{~W}$. The estimated nickel contents are respectively 66,44 and $32 \mathrm{wt}$ $\%$. The characteristics in the same media for mild steel and electroless nickel coating are also given for 
comparison. Figure 2 clearly shows the following order of decreasing behaviour : I $>$ II $>$ III $>$ mild steel. This classification corresponds also to the nickel content in the surface alloys. Figure 2 also shows that the behaviour of sample I is slightly better than the electroless nickel one, in spite of a non negligible iron content and the presence of interdendritic phosphides. This behaviour can be attributed to the elimination of defects or impurities by the laser melting.

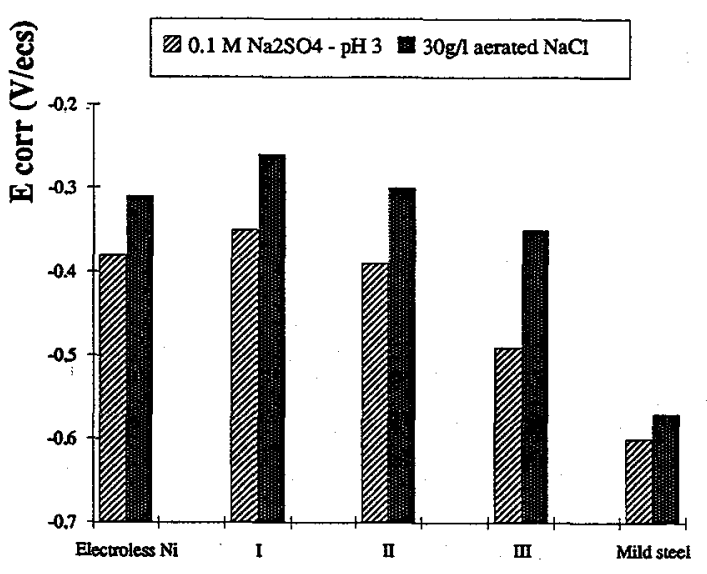

(a)

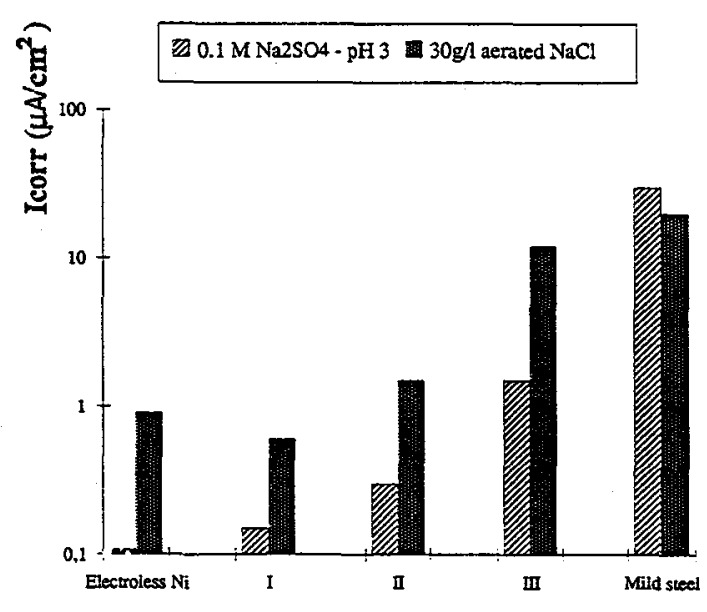

(b)

Fig. 2. Electrochemical measurements a - Free corrosion potential ( $\left.\mathrm{E}_{\text {corr. }}\right)$, b - Corrosion current density ( $\left.\mathrm{I}_{\text {corr }}\right)$

\section{Electroless nickel containing chromium carbides ( $\mathrm{Cr} 3 \mathrm{C} 2)$}

In order to increase the corrosion resistance of such laser surface alloys, we incorporate chromium by means of chromium carbide particles in the electroless deposit prior to laser melting. This co-deposition is a simple, economic process for introducing chromium and it is already industrially used. Chromium carbide particles are expected to dissolve in the melt pool during laser treatment and to release chromium in this melt pool.

In this case, we also obtained good quality surface alloys (free of pores and cracks). The results of the microstructural analysis showed that the dendrites are an austenitic $\mathrm{Fe}-\mathrm{Ni}$ - $\mathrm{Cr}$ solid solution. Interdendritic areas are composed of $(\mathrm{Fe}, \mathrm{Ni}, \mathrm{Cr}) 3 \mathrm{P}+(\mathrm{Fe}, \mathrm{Ni}, \mathrm{Cr}$ ) eutectic mixture in which are embedded partially dissolved $\mathrm{Cr} 3 \mathrm{C} 2$ particles together with precipitated ( $\mathrm{Fe}, \mathrm{Cr}) 7 \mathrm{C} 3$ particles [3]. The maximum chromium content obtained in the surface alloy was 4 to $5 \mathrm{wt} \%$. This maximum content results from a competition between the dissolution kinetic and the $\mathrm{M} 7 \mathrm{C} 3$ precipitation kinetic.

Consequently, the corrosion resistance was only slightly improved. Hence another way has to be followed in order to achieve higher corrosion resistant surface alloys.

\section{Double-layers deposits}

Two types of nickel + chromium bilayers were performed prior to laser melting. The difference provides from the nature of the nickel deposition : either electroless or electrolytic. With electroless nickel, there is an important difference in melting point $\left(1100^{\circ} \mathrm{C}\right)$ with the above chromium layer $\left(1860^{\circ} \mathrm{C}\right)$, and so, for a given laser power, either complete melting is not reached or, if it is achieved, the melted depth is important leading to a large dilution. With electrodeposited nickel, the difference of melting points between the two layers is much lower than in the previous case (respectively 1450 and $1860^{\circ} \mathrm{C}$ ). This is why less diluted alloys were obtained when nickel was electrodeposited. As an example table 1 gives laser processing conditions for the two best obtained surface alloys IV and V for these two types of precoatings.

These two samples exhibited a high corrosion resistance in $30 \mathrm{~g} / 1 \mathrm{NaCl}$ solutions . Sample $\mathrm{V}$, obtained with electrodeposited nickel, exhibits the best behaviour and a real ability to passivation. This is due to higher chromium and nickel contents and to the absence of phosphorous. 
Table 1: Laser parameters for obtaining the surface alloys IV (predeposits : electroless Ni -P + electrolytic $\mathrm{Cr}$ ) and $\mathrm{V}$ (predeposits : electrolytic $\mathrm{Ni}+$ electrolytic $\mathrm{Cr}$ )

$\mathrm{P}$ : laser power, VT moving rate of the table, $e_{\mathrm{Ni}}$ and $\mathrm{e}_{\mathrm{Cr}}$ predeposit thicknesses, $\mathrm{e}_{\mathrm{f}}$ melted layer thickness

\begin{tabular}{cccccccc}
\hline & $\begin{array}{c}\mathrm{P} \\
(\mathrm{W})\end{array}$ & $\begin{array}{c}\mathrm{VT} \\
\left(\mathrm{cm} \cdot \mathrm{s}^{-1}\right)\end{array}$ & $\begin{array}{c}\mathrm{e}_{\mathrm{Ni}} \\
(\mu \mathrm{m})\end{array}$ & $\begin{array}{c}\mathrm{e}_{\mathrm{Cr}} \\
(\mu \mathrm{m})\end{array}$ & $\begin{array}{c}\mathrm{e}_{\mathrm{f}} \\
(\mu \mathrm{m})\end{array}$ & $\begin{array}{c}\mathrm{Ni} \\
\text { wt \% }\end{array}$ & $\begin{array}{c}\mathrm{Cr} \\
\text { wt \% }\end{array}$ \\
\hline $\mathrm{IV}$ & 1640 & 20 & 39 & 35 & 210 & 17 & 15.5 \\
$\mathrm{~V}$ & 1450 & 20 & 38 & 34 & 155 & 25 & 22 \\
\hline
\end{tabular}

\section{Conclusion}

By laser remelting of an electroless $\mathrm{Ni}$ - P coating on a mild steel, it is possible to obtain a good quality surface alloy i.e. free of pores or cracks. This treatment eliminates eventually preexisting cracks or pores of the initial coating without decreasing the corrosion resistance. Once this possibility to realize such treatments was established, other types of precoatings were used in order to introduce chromium. The first one was an electroless nickel layer containing $\mathrm{Cr} 3 \mathrm{C} 2$ chromium carbides. Only a slight increase in corrosion resistance was obtained. This is due to the fact that only a maximum of $5 \mathrm{wt} \% \mathrm{Cr}$ in solid solution was obtained because of partial dissolution of previous carbides combined with a precipitation of M7C 3 type carbides. The second type of precoatings was $\mathrm{Ni}+\mathrm{Cr}$ double-layers with nickel either electroless or electrodeposited. Surface alloys obtained with both type of precoatings exhibited a high corrosion resistance in $30 \mathrm{~g} / 1 \mathrm{NaCl}$ aerated solution. Nevertheless the best results were obtained when nickel was electrodeposited due to high chromium and nickel contents $(22 \mathrm{Cr}-22 \mathrm{Ni})$ and the absence of phophorous. However electroless deposits present the advantage of easier realization and higher regularity in thickness. This is to be taken into account for further development of this laser treatment process.

\section{References}

/1/ TULSI, S.S, "Properties of electroless nickel", Trans. IMF, 1986, Vol. 64, p. 73-76.

/2 / SALVAGO, S, and FUMAGALLI, G, "Electroless nickel defects, passivity and localized corrosion", Metals Finishing, 1987, Vol. 85, n³, p. 31-35.

/3/ RENAUD, L, Doctorate Thesis, INSA, nº 90 ISAL 0082, LYON, 1990.

/4/ RENAUD, L, FOUQUET, F, ELHAMDAOUI, A, MILLET, J.P, MAZILLE,H and CROLET, J.L, "Surface alloys obtained on mild steel by laser treatment of electroless nickel coatings", Acta Metall. Mater., 1990, Vol. 38, nº, p. 1547-1553.

15/ RENAUD, L, FOUQUET, F, MILLET, J.P, MAZILLE,H and CROLET, J.L "Microstructural characterization and comparative electrochemical behavior of $\mathrm{Fe}-\mathrm{Ni}-\mathrm{Cr}$ and $\mathrm{Fe}-\mathrm{Ni}-\mathrm{Cr}$-P laser surface alloys", 7th. Intern. Conf. on Rapidly Quenched Materials, Stockolm, 1990, Mater. Sci. Eng, 1991, Vol. A 134, p. 1049 - 1053.

/6/ RENAUD, L, FOUQUET, F, MILLET, J.P, MAZILLE, $H$ and CROLET, J.L, "Surface alloying of mild steel by laser melting of an electroless nickel deposit containing chromium carbides", Mater. and Manufact. Proc., 1991, Vol. 6, n², p. 315 - 330. 